ARTIGO

\title{
Literatura e atenção: notas sobre um novo regime de percepção no ensino de literatura
}

André Cechinel' (D)

\section{RESUMO}

Com a publicação da nova Base Nacional Comum Curricular (BNCC) de 2018 e da profusão de mídias e dispositivos ali associados ao ensino de literatura, o presente artigo propõe-se a discutir a chamada crise da atenção na modernidade e de que modo ela afeta o gesto específico solicitado pelo contato com os artefatos literários. Em poucas palavras, se a leitura literária, por um lado, se vincula tradicionalmente ao autocentramento, à concentração, ao silêncio e a outras formas de introspecção, a nova BNCC, por outro, posiciona a literatura num território de constantes deslocamentos e adaptações intermidiáticas, num deslizamento contínuo que inevitavelmente produz consequências para o domínio da atenção e da percepção e compreensão leitora.

PALAVRAS-CHAVE

literatura; percepção; atenção; Base Nacional Comum Curricular.

Universidade do Extremo Sul Catarinense, Criciúma, SC, Brasil. 


\title{
LITERATURE AND ATTENTION: NOTES ON A NEW PERCEPTION REGIME IN THE TEACHING OF LITERATURE
}

\begin{abstract}
Based on the publication of the new Common National Curricular Basis of 2018 and the profusion of media and devices associated with the teaching of literature, this article intends to discuss the so-called attention crisis in modernity and how it affects the specific gesture requested by the contact with literary artifacts. In a few words, if literary reading, on the one hand, is traditionally linked to self-centering, concentration, silence, and other forms of introspection, the new BNCC, on the other hand, places literature in a territory of constant displacements and intermedia adaptations, introducing a continuous movement that inevitably produces consequences for the domain of attention and the reader's perception and understanding.
\end{abstract}

KEYWORDS

literature; perception; attention; Base Nacional Comum Curricular.

\section{LITERATURA Y ATENCIÓN: NOTAS SOBRE UN NUEVO RÉGIMEN DE PERCEPCIÓN EN LA ENSEÑANZA DE LA LITERATURA}

\section{RESUMEN}

A partir de la publicación de la nueva Base Nacional Común Curricular de 2018 y de la profusión de medios y dispositivos allí asociados a la enseñanza de literatura, el presente artículo se propone discutir la llamada crisis de la atención en la modernidad y de qué modo afecta el gesto específico solicitado por el contacto con los artefactos literarios. En pocas palabras, si la lectura literaria, por un lado, se vincula tradicionalmente al autocentrado, a la concentración, al silencio y a otras formas de introspección, la nueva $\mathrm{BNCC}$, por otro, posiciona la literatura en un territorio de constantes desplazamientos y adaptaciones intermidiáticas, en un deslizamiento continuo que inevitablemente produce consecuencias para el dominio de la atención y de la percepción y comprensión lectora.

PALABRAS CLAVE

literatura; percepción; atención; Base Nacional Comum Curricular. 


\section{INTRODUÇÃO}

Qualquer reflexão consequente sobre o declínio do prestígio do ensino de literatura há que deparar, inevitavelmente, com os impasses hoje constitutivos da área, como a crise do discurso de nação ou do paradigma nacionalista como fio condutor e explicativo para a experiência literária; a perda de centralidade ou da objetividade imediata conferida por um cânone antes autocentrado e agora associado a um processo histórico tanto ideológico quanto estetizante, responsável por excluir do campo das letras diferentes grupos minoritários, como negros e mulheres; a insuficiência e parcialidade das tentativas de definir a literariedade ou literaturidade da literatura por meio de explicações internas, imanentes ou formais, a exemplo daquelas buscadas por círculos hermenêuticos como o formalismo russo, a nova crítica, o estruturalismo, entre outros; a "evaporação" da literatura e de seus artefatos - ao menos tal como concebidos por determinada tradição - , como resultado do alargamento conceitual do literário, promovido tanto pelos estudos culturais quanto por uma noção vaga de textualidade, ou, ainda, pela passagem da teoria literária para algo chamado simplesmente de Teoria, com $t$ maiúsculo e sem objetos específicos (cf. Durão, 2011); e, por fim, o fato mais óbvio, de que no Brasil se lê muito pouco, constatação que se intensifica uma vez eliminados do horizonte da leitura contatos mais fugazes ou fragmentários como aqueles proporcionados por Facebook, Twitter e tutti quanti. ${ }^{1}$ A lista, que poderia ser ampliada, sinaliza, enfim, que a crise do ensino de literatura, ou da própria literatura e dos estudos literários, é um fenômeno complexo, decorrente de múltiplos vetores que se atravessam e que não se revelam integralmente se analisados como casos isolados.

Ora, para além dos desdobramentos internos da área, conforme brevemente listados, outro elemento que contribui para agravar a dimensão e o alcance dessa crise diz respeito a algo que poderíamos chamar de problema da atenção ou

1 Segundo os dados da quarta edição da pesquisa Retratos da leitura no Brasil, realizada pelo Instituto Pró-Livro e divulgada em 2016, 44\% da população brasileira não lê e 30\% nunca comprou um livro. A média de leitura dos brasileiros é de 4,96 livros por ano, e entre os volumes mais citados pelos participantes da pesquisa estão a Bíblia, Diário de um banana, Casamento blindado, A culpa é das estrelas, Cinquenta tons de cinza, Ágape, Esperança, O monge e o executivo, Ninguém é de ninguém, Cidades de papel, $O$ código da inteligência, Livro de culinária, Livro dos espiritos, A maldição do titã, A menina que roubava livros, Muito mais que cinco minutos, Philia e $A$ única esperança. Já os autores mais citados são os seguintes: Augusto Cury, João Ferreira de Almeida, Zibia Gasparetto, Padre Marcelo Rossi, Cristiane Cardoso/Cristiane e Renato Cardoso, Paulo Coelho, Allan Kardec, John Green, Chico Xavier, Ellen G. White, Machado de Assis, Padre Fábio de Melo, Maurício de Sousa, Bispo Edir Macedo e Kéfera Buchmann. Quanto ao uso e à destinação do tempo livre, a leitura fica em décimo lugar, atrás de: 1) assistir à televisão,2) ouvir música, 3) usar a internet, 4) reunir-se com amigos ou família ou sair com amigos, 5) assistir a vídeos ou filmes em casa, 6) usar WhatsApp, 7) escrever, 8) usar Facebook, Twitter ou Instagram, 9) ler jornais, revistas ou notícias (Instituto Pró-Livro ,2016). 
percepção. Em outras palavras, se a leitura literária, por um lado, costuma estar vinculada a um exercício principalmente individual, autocentrado e solitário, que demanda atenção, esforço e concentração, aquilo que conhecemos como modernidade tardia ou pós-modernidade, por outro lado, é caracterizado pela imagem da dispersão, do consumo rápido, do descarte e do fluxo, de tal forma que o conhecimento de fôlego a ser incentivado e praticado na escola se vê cada vez mais inviabilizado por uma nova dinâmica leitora, repleta de estímulos, imagens e sons em profunda sintonia com a "sociedade excitada" do tempo presente. Ao mesmo tempo que as subjetividades formadas nesse contexto são incentivadas, a todo instante, a produzir discursos de si alinhados à lógica da inovação e do empreendedorismo individual (cf. Dardot, Laval, 2016), essa construção subjetiva, urdida nesses termos, é muito mais provisória do que aquela solicitada e fabricada pela temporalidade literária, o que resulta num impasse perceptivo de modo geral pouco produtivo ou auspicioso para a literatura.

O presente texto, motivado pela recente publicação da nova Base Nacional Comum Curricular (BNCC) para o ensino médio, cujas formulações sobre o ensino de literatura se vinculam significativamente a "processos que envolvem adaptações, remidiações, estilizações, paródias, HQs, minisséries, filmes, videominutos, games etc." (Brasil, 2018, p. 492), propõe-se a debater a relação entre a pluralidade e a abundância de mídias, gêneros, plataformas e produções citadas aqui e ali pelo documento e o problema específico da vivência sensorial e perceptiva fundamental para o contato com a complexidade e singularidade das obras literárias. Cabe explicar: se a BNCC, talvez pela primeira vez num documento oficial do Ministério da Educação (MEC), alarga o conceito de literatura para incluir no escopo de suas atividades, por exemplo, "resenhas, vlogs e podcasts literários, culturais etc. [...] Remidiações, paródias, estilizações, videominutos, fanfics etc." (Brasil, 2018, p. 495), é certo que essa multiplicidade de manifestações artístico-literárias, bem como seus respectivos gêneros e mídias, ativa um mecanismo complexo de adaptações e deslocamentos contínuos dos quais a sensibilidade sensorial dos alunos dificilmente sairá inalterada. Assim, a aula de literatura contorna o cenário de sua crise ao mesmo tempo que amplia o domínio de atuação dos seus sintomas.

Para tanto, a fim de analisar esse impasse, o argumento divide-se em dois momentos principais: primeiramente, volta-se tanto para o problema da atenção na modernidade, sobretudo com base em pontos-chave das reflexões de Jonathan Crary $(2013,2014)$, quanto para o surgimento da "sociedade excitada" e do paradigma da sensação na contemporaneidade (cf. Türcke, 2010); e, a seguir, o texto investiga os diferentes dispositivos sensoriais e fluxos adaptativos acionados pela BNCC e de que modo eles se aproximam, se distanciam e, acima de tudo, afetam a leitura propriamente literária conforme antes descrita. O que se espera demonstrar, em suma, é que os encaminhamentos práticos expostos na BNCC, ao oferecer alternativas plurimidiáticas e intercambiáveis entre si para o ensino de literatura, evitam os debates mais caros aos estudos literários e mergulham de vez a tradição e o cânone na própria crise da leitura que os teóricos não cansam de anunciar nem de denunciar. 


\section{MUTAÇÕES SENSORIAIS E OS USOS DA ATENÇÃO}

Em texto de 1926 intitulado "Culto da distração", presente no livro O ornamento da massa, Siegfried Kracauer investiga o que compreende como um crescente "culto da distração" com base em um sintoma ou fenômeno, a princípio, bastante corriqueiro, a ascensão dos grandes "cineteatros" na Alemanha da década de 1920, espaços marcados por um "esplendor da superfície", um "bombardeio de impressões" que substitui a mera projeção de um filme após o outro. $\mathrm{O}$ signo essencial dos cineteatros é o da abundância, formando uma "obra de arte total dos efeitos [que] se desencadeia com todos os meios diante de todos os sentidos" (Kracauer, 2009, p. 344). Ao filme, antes presente como unidade autossuficiente, acrescentam-se várias outras dimensões artísticas e sensoriais, a exemplo dos refletores, que lançam luzes em determinados pontos do ambiente, da orquestra, que tem uma vida como que autônoma no espaço, da música, das cores, da pantomima, do balé etc. Assim, com essa política do excesso de "magia" visual e sonora, as antigas salas de cinemas convertem-se em recintos, quando não obsoletos, pelo menos antiquados ou mesmo desestimulantes, entediantes. A consequência diagnosticada por Kracauer (2009), no entanto, não é precisamente elogiosa para os cineteatros: como resultado de um espaço que promove a agitação contínua dos sentidos, metralhando a percepção de excitações audiovisuais, a reflexão e o entendimento saem prejudicados, uma vez que já não há mais tempo para a interrupção que corta o fluxo e antecipa o pensamento. O que o autor define como um "culto da distração", em suma, tem a ver não com a falta ou com a ausência, mas sim com o seu contrário, um acúmulo ou profusão de produções cujo prazer promovido se associa de imediato a uma apatia anestesiante que mutila a posição crítica do espectador diante daquilo que vê.

Embora discorde em parte da tradição filosófica que passa por Georg Simmel, Walter Benjamin, pelo próprio Siegfried Kracauer, por Theodor Adorno e demais autores que "presumiam que a percepção distraída era fundamental para qualquer explicação da subjetividade moderna” (Crary, 2013, p. 72) — nomes que descreviam a modernidade fundamentalmente como um processo de fragmentação, destruição, regressão, perda, decadência e atrofia da percepção, naturalizando, desse modo, formas anteriores supostamente imbuídas de "valores existentes durante séculos" - Jonathan Crary (2013) compreende que a atenção constitui uma categoria decisiva para pensar a experiência sensorial na modernidade capitalista, tendo o tema se tornado um problema objetivo a ser cientificamente administrado já no fim do século XIX. Em linhas gerais, segundo o argumento de Crary (2013), a relação entre atenção e distração deve ser compreendida como um continuum que se movimenta de um lado para o outro de acordo com "a introdução ininterrupta de novos produtos, novas fontes de estímulo e fluxos de informação", que, por sua vez, introduzem "novos métodos para administrar e regular a percepção"(Crary, 2013, p. 36). Em outras palavras, a inclusão de diferentes formas ou modos de circulação da informação ou de produtos gera respostas específicas do ponto de vista do controle da atenção, respostas que podem, até mesmo, em muitos casos, não dar conta de adequar as subjetividades formadas às novas demandas perceptivas. O capitalismo, com suas trocas cada vez mais rápidas, torna-se "um regime de atenção e distração 
recíprocas" (Crary, 2013, p. 53), em que as sobrecargas sensoriais produzem um curto-circuito na percepção e fazem com que o continuum se desloque ininterruptamente de um lado para outro. Menos que distração apenas, caberia falar em exaustão ou "errância da atenção":

Nos últimos cem anos, as modalidades perceptivas têm se encontrado - e assim continuam - num estado constante de transformação, ou, como diriam alguns, num estado de crise. Se é possível dizer que a visão teve alguma característica constante ao longo do século XX, esta seria precisamente a falta de características constantes. Ao contrário, a visão está imersa em um padrão de adaptabilidade a novas relações tecnológicas, configurações sociais e imperativos econômicos. Aquilo que, por exemplo, costumamos chamar de cinema, fotografia e televisão são elementos transitórios em uma sequência acelerada de deslocamentos e obsolescências que são parte das operações delirantes da modernização. (Crary, 2013, p. 35, grifo meu)

Pode-se dizer que a palavra central aqui é adaptabilidade, isto é, a capacidade de manter a atenção estimulada e o sujeito condicionado a um lance contínuo de substituições, adaptações, equivalências, trocas e ciclos cada vez mais acelerados e instáveis. Esse regime de deslocamento constante da atenção de um lugar para outro produz uma sobrecarga perceptiva prejudicial à atenção, que depois de certo tempo volta a ser assombrada pela distração e pela necessidade de um novo giro no mecanismo da velocidade e das novidades para se sentir uma vez mais excitada. Eis o paradoxo ou dano inevitável desse jogo: para ativar o consumo, é preciso despertar ou dirigir a atenção a determinado objeto; no entanto, como a atenção por muito tempo retida sobre um único objeto significa a desaceleração do consumo e prejuízo econômico para a dinâmica do capital, resta, depois de certo intervalo, deslocá-la para um segundo artefato, num esquema que inevitavelmente conduz a uma pane da atenção à medida que progride a sua aceleração. A transitoriedade dos estímulos estabelece um funcionamento ininterrupto da maquinaria, um fluxo contínuo, porém imprevisível, que tem por correlato objetivo a perda gradativa da concentração, a impossibilidade de interiorizar a experiência e, em seu ponto mais alto, o sonambulismo, o automatismo, a separação, o isolamento, a apatia, ou, então, aquilo que leva o nome de tédio, um tédio que para se desfazer solicita novos deslocamentos perceptivos e sensoriais, reinaugurando essa mesma cadeia de eventos. Importante aqui ressaltar que o fenômeno que Guy Debord (2017) nomeou em 1967 como "sociedade do espetáculo" se dirige ao império da circulação de produtos e imagens e a uma "baixa tendencial do valor de uso", ou seja, à precarização da noção de uso e da capacidade de mobilizar os objetos em sua singularidade e vinculação ao cotidiano, resultado do império das trocas e da equivalência e intercambialidade das mercadorias.

As últimas décadas do século XX e, pode-se dizer sem medo de errar, as duas primeiras décadas do século XXI apenas consolidaram esse quadro de "renúncia à pretensão de que o tempo possa estar acoplado a quaisquer tarefas de longo prazo" (Crary, 2014, p. 19). Os discursos neoliberais de criatividade, gestão empresarial, 
inovação, empreendedorismo, coaching, mentoring etc. - termos antes dirigidos a corporações, mas hoje entranhados na própria subjetividade dos sujeitos, ou já introjetados em seu código genético, materializando a ideia de um eu empresa ou um $e u$ empresarial - apenas consolidam a tese de que a estabilidade, a lentidão, a inatividade, a intransitividade, o silêncio, o uso, o descanso, o sono, a solidão e o pensamento são obstáculos indesejáveis para o ritmo acelerado do consumo e do descarte segundo os termos antes descritos. Na bolsa de valores da sensibilidade contemporânea, estão em baixa todas as práticas e os hábitos que não se convertem tão facilmente em mercadoria, como é o caso do sono segundo o argumento de Crary (2014). Ao contrário da fome, da sede, do desejo sexual e da amizade, entre outras necessidades básicas capitalizadas pelo utilitarismo contemporâneo, o sono permaneceria "um hiato incontornável no roubo do tempo" (Crary, 2014, p. 20). Valeria a pena, contudo, submeter a tese do autor à apreciação das grandes redes hoteleiras espalhadas ao redor do mundo, que fazem do sono e do conforto parte decisiva de seu negócio. Seja como for, nas palavras de Crary (2014, p. 48), “a experiência e a percepção estão sendo reconfiguradas pelos ritmos, velocidades e formas de consumo acelerado e intensificado", e o que quer que o impeça é retirado imediatamente da paisagem social.

Chamemos isso de "sociedade do cansaço", como o filósofo sul-coreano Byung-Chul Han (2015) o faz, de "novo espírito do capitalismo", na concepção de Boltanski e Chiapello (2009), de "nova razão do mundo", nos termos de Dardot e Laval (2016), ou então simplesmente de "sociedade excitada", conforme a nomenclatura de Christoph Türcke (2010), o certo é que é o próprio estatuto ontológico do sujeito que parece ter-se alterado com os atuais ritmos, redes e dispositivos de circulação de mercadorias e formas de consumo. São as pessoas que agora, em certa medida, se convertem elas mesmas em campos de produção de excitações e estímulos sensoriais, tendo sua existência publicamente afirmada, confirmada ou negada de acordo com o seu indice de irradiação particular, medido e verificado, entre outros, por ferramentas como Facebook e Twitter, voluntariamente preenchidas pelos usuários que gerenciam e atualizam de modo obediente suas zonas privadas de emissão, que são também microempresas de si. Nas palavras de Türcke (2010, p. 48), "fala-se muito da falta de dinheiro, mas da falta de 'aí', quase nada. No entanto, ela é demonstrada em grande escala: da maneira como uma sociedade inteira se sente compelida a aparecer em emissões, a exigir atenção, a criar uma sensação”. É da mais profunda falta de "aí", ou seja, de uma existência que não se vê comprovada em sua condição emissora, em suma, que sofrem os diferentes "desalentados"2 ou excluídos de hoje,

2 Nos dados referentes ao crescente número de desempregados no Brasil, a categoria dos chamados desalentados, que hoje (outubro de 2018) soma cerca de 4,8 milhões de pessoas sem vínculo empregatício nenhum, não entra na contagem oficial. Os desalentados são aqueles que desistiram de procurar emprego e que, dessa forma, saem da estatística dos desempregados. Em outras palavras, para constituir parte dos desempregados, faz-se necessário um quantum mínimo de irradicação que, sem ser produzido, atesta a inexistência social dos desalentados. 
sujeitos incapazes de aparecer como produtivos, úteis e irradiadores de luminosidade nos campos de visibilidade social.

O desdobramento final desse quadro não nos é estranho: lado a lado com a conquista absoluta de todos os âmbitos da existência humana por um capitalismo desenfreado e autônomo, incapaz de cumprir as promessas que não deixa de diariamente renovar, caminham a desigualdade cada vez mais escandalosa, a devastação ambiental, as guerras, as inúmeras doenças e violências neuronais, a obediência acrítica e antecipada, a mutilação dos conceitos de democracia e comunidade, a competição generalizada, a indiferença, a conversão do indivíduo em empresa e tantas outras conhecidas formas de precarização da vida. Tudo isso faz com que o filósofo francês Frédéric Gros lance as inevitáveis perguntas: "Por que, diante da iminência da catástrofe, ainda ficamos hoje de braços cruzados e com os olhos, nem digo resignados, mas tentando desviá-los para outro lado? Por que deixamos a coisa correr, por que nos comportamos como espectadores do desastre?" (Gros, 2018, p. 15-16). Ora, se a literatura parece algo muito pequeno diante de tudo isso - e ela de fato o é - , é certo que o seu posicionamento em meio a um mundo de artefatos, formas e artifícios intercambiáveis entre si representa um alinhamento à lógica do capital, da equivalência e das trocas constantes e, com isso, uma distância definitiva tomada em relação a sua suposta singularidade, a mesma singularidade até recentemente julgada imprescindível para a tão propalada formação bumana.

\section{PLURALIDADE MIDIÁTICA, LITERATURA E ATENÇÃO}

Para evidenciar a distância que a BNCC toma de processos intransitivos ou dimensões formativas que não se conectam de imediato ao utilitarismo do mundo produtivo vislumbrado anteriormente, talvez bastasse observar que o documento se estrutura, todo ele, sobre uma lógica enrijecida de meios e fins, ou melhor, sobre um mecanismo de promoção de "competências e habilidades" que tem por intuito "resolver demandas complexas da vida cotidiana, do pleno exercício da cidadania e do mundo do trabalho" (Brasil, 2018, p. 8). Talvez coubesse até mesmo indicar que, já na própria formulação inicial do texto, o "pleno exercício da cidadania" surge sintomaticamente comprimido entre as "demandas complexas da vida cotidiana" e aquelas "do mundo do trabalho" (Brasil, 2018, p. 8). Por fim, provavelmente fosse necessário assinalar que competência é um dos termos incontornáveis ditados pelo Instituto Ayrton Senna (IAS) e pela Organização para a Cooperação e Desenvolvimento Econômico (OCDE) em documentos sobre a educação e seu vínculo com as "competências cognitivas e socioemocionais" que crianças e adolescentes precisam dominar "para ser bem-sucedidos na vida moderna" (OCDE, 2015, p. 3). No entanto o objetivo aqui é outro; não é analisar a BNCC como um todo, mas sim e tão somente entender como o documento insere a literatura em redes plurimidiáticas e pluriespaciais que não recebem singularização nenhuma quanto ao seu papel ou funcionamento específico, operando aparentemente como meros vetores de trocas e deslocamentos sem um objeto ou conteúdo particular em vista.

As menções à literatura na BNCC não chegam a ser muitas ou excessivas - mesmo com todas as modificações realizadas em relação ao texto das Orienta- 
çôes curriculares para o ensino médio (Brasil, 2006), não há, por exemplo, nenhuma tentativa mínima que seja de particularização de uma área de estudos, talvez por conta da dimensão interdisciplinar ali adotada - o que não impede o documento de fazer desfilar diante do leitor uma série de gêneros, mídias, produções e processos entre os quais aparecem:

Adaptações, remidiações, estilizações, paródias, HQs, minisséries, filmes, videominutos, games [...] [;] obras artísticas e produções culturais (resenhas, vlogs e podcasts literários, culturais etc.) ou formas de apropriação do texto literário, de produções cinematográficas e teatrais e de outras manifestações artísticas (remidiações, paródias, estilizações, videominutos, fanfics etc.) [...] [;] perfis, apresentações pessoais, relatos autobiográficos, mapas (e outras formas de registro) comentados e dinâmicos, almanaques, playlists comentadas de produções culturais diversas, fanzines, $e$-zines [...] [;] slams, vídeos de diferentes tipos, playlists comentadas, raps e outros gêneros musicais etc., minicontos, nanocontos, best-sellers, literatura juvenil brasileira e estrangeira, incluindo entre elas a literatura africana de língua portuguesa, a afro-brasileira, a latino-americana etc., obras da tradição popular (versos, cordéis, cirandas, canções em geral, contos folclóricos de matrizes europeias, africanas, indígenas etc.) [...] [;] saraus, competições orais, audições, mostras, festivais, feiras culturais e literárias, rodas e clubes de leitura, cooperativas culturais, jograis, repentes, slams etc. [...] poemas, contos e suas variedades, roteiros e microrroteiros, videominutos, playlists comentadas de música etc. (Brasil, 2018, p. 492-515)

Muito embora por vezes constituam desdobramentos possíveis mediante o contato com o literário, essa pirotecnia midiática contrasta significativamente com qualquer caracterização ou concepção da aula de literatura ou da leitura como atividades vinculadas à introspecção, à concentração ou a uma "forma de sair de si mesmo e do ambiente que nos rodeia, mas também de conhecer-se melhor e ser mais consciente de nossa ordem e desordem" (Berardinelli, 2016, p. 21). De um deslocamento subjetivo e arriscado, passa-se, pois, a uma desierarquização completa dos objetos e espaços, bem como a um deslocamento antes de mais nada físico, seja do olhar, seja do próprio corpo. Se o estudo é aquilo que interrompe, "é o dom ambíguo, fascinante e perigoso, do estupor que produz a suprema interrupção" (Larrosa, 2015, p. 200), o excesso de mídias que surgem como unidades autorreferenciais canaliza os esforços dos alunos e professores, como dito, para o âmbito dos vetores em si, e não para o que concretizam como experiência literária da interrupção.

Para citar um exemplo evidente disso, a BNCC dirige-se repetidas vezes ao domínio da crítica literária, à leitura que os alunos fazem de seu contato com os artefatos artísticos, recomendando, para fins de veiculação da apreciação, apropriação ou recriação dessa experiência, o uso de resenhas, vlogs, podcasts, remidiações, paródias, estilizações, videominutos, fanfics etc. A variedade de alternativas, entretanto, faz saltar ainda mais aos olhos a absoluta ausência de discussões conceituais sobre a tarefa intelectual ou a função social da crítica literária, sobre como compreender o funcionamento de um texto, suas regras, seus laços intertextuais, suas implica- 
ções sociais, a relação entre autor, obra e leitor, isso para citar apenas algumas das discussões caras à teoria literária. Sem uma reflexão mais apurada nessa direção, isto é, sem um aprofundamento do fato de que a crítica e a interpretação tendem "a implicar algum espaço concreto de veiculação e a consequente existência de um público leitor, de uma esfera pública na qual se inserirá”(Durão, 2016, p. 11, grifos do autor), fixamo-nos, então, no campo subjetivo da expressão do gosto individual e de sua comunicação descompromissada, via de regra desvinculada de uma apreciação ou valoração minimamente objetiva, imanente e criteriosa da experiência estética cujo ensino e aprendizagem são ou deveriam ser tarefas da escola. Resta, assim, a desconfortável sensação de que, nesse exercício, importa menos a densidade do que será dito do que a ocupação efetiva de um diferente número de mídias, tomadas como entidades autossuficientes e importantes em si mesmas, independentemente de um modo específico de afetar o literário, ainda que a princípio no campo da literatura já não estejamos tão longe da esfera confessional há muito familiar aos alunos e cultivada pelas mídias sociais.

Em seu estudo intitulado Uma teoria da adaptação, Linda Hutcheon insiste repetidamente no fato de que "a arte deriva de outra arte; as histórias nascem de outras histórias" (Hutcheon, 2011, p. 22), e que, dessa forma, estamos sempre deslizando de um espaço para outro, pois, "nas operações da imaginação humana, a adaptação é a norma, não a exceção" (Hutcheon, 2011, p. 235). O que particulariza a adaptação como adaptação, entretanto, para além da passagem de uma narrativa à outra, é o fato de que cada encarnação midiática arrasta consigo especificidades de gênero e de mídia. Ou seja, estudar a adaptação é, inevitavelmente, compreender as implicações teóricas decorrentes dos diferentes tipos de engajamento e modos de interagir solicitados do leitor segundo as funções constitutivas de cada "remidiação". É por isso que a autora divide a sua investigação em três "modos de engajamento", o "contar", o "mostrar" e o "interagir": "quando uma mudança de mídia, de fato, ocorre numa adaptação, ela inevitavelmente invoca a longa história de debates em torno da especificidade formal das artes - e, assim, das mídias" (Hutcheon, 2011, p.62). O movimento entre as mídias institui um debate imprescindível sobre o que se acrescenta e o que se perde com cada uma delas - do "contar" para o "mostrar", por exemplo, passamos geralmente do impresso para o performativo e, com isso, do silêncio das palavras da página para a performance, os gestos, as imagens, os tons de voz, a música etc. Da mesma maneira, do "contar" ou "mostrar" para o "interagir", deixamos o campo da página impressa ou da performance para uma participação mais imediata ou deliberada do usuário, tal como ocorre nos jogos computadorizados, videogames, narrativas interativas etc. Modificada a mídia, em suma, modificam-se também as regras do jogo. Diante desse quadro, se a compreensão é a de que o literário não se conecta a uma plataforma de leitura específica - tal como a BNCC parece indicar -, o desafio consiste então em debater as mudanças provocadas pelas particularidades de mídia e contexto, empresa que o documento está longe de assumir.

Um dos aspectos frequentemente enfatizados no discurso sobre "formação humana" por meio do contato com os artefatos literários diz respeito a um suposto "autodescobrimento" "em termos de elaboração da subjetividade e das 
inter-relações pessoais" (Brasil, 2018, p. 496). Nesse sentido, a literatura possibilitaria "a autonomia intelectual e o pensamento crítico" (Brasil, 2006, p. 53), o que corresponde à "humanização" do ser humano na formulação, entre outros, de Antonio Candido (2011), crítico não raro citado nos documentos aqui em pauta. Apesar de as teses sobre a humanização decorrente da leitura literária carecerem elas próprias de uma discussão teórica mais aprofundada, principalmente por pressupor um conteúdo positivado que as obras em si não deixam de contestar ou violentar, essa autonomia ou formação humana estaria associada, acima de tudo, à imaginação, à reflexão, à interiorização, à introspecção, à abstração, à fruição estética etc. Contudo, uma das coisas que Jonathan Crary destaca acerca da velocidade, da aceleração, do acúmulo, da multiplicidade de estímulos sensoriais, do constante deslizamento de uma tecnologia para outra e da "sucessão irregular de instantes de concentração e de atenção passageira” (Crary, 2014, p. 136) é, sintomaticamente, a impossibilidade de interiorização ou de elaboração da subjetividade, ou seja, o mergulho do sujeito num regime de fluxos em que, menos que se "formar", a individualidade se vê "virada do avesso, invertida para uma condição de exteriorização" (Crary, 2013, p. 105). Esses trânsitos contextuais e intermidiáticos, quando automatizados, tomados como um fim em si mesmos e destituídos de qualquer reflexão mais cuidadosa, convertem-se em ferramentas de exteriorização e de eliminação da intimidade, permitindo o conhecimento das plataformas, vetores e dispositivos tecnológicos, mas desestimulando a percepção e a formulação mais aprofundadas de si, essenciais a qualquer noção consequente de formação.

\section{CONSIDERAÇÕES FINAIS}

Em seu livro de 1977 chamado Velocidade e politica, Paul Virilio anuncia a chegada daquilo que ele nomeia como uma "revolução dromocrática", isto é, o domínio cada vez mais integral do "país da velocidade" sobre as categorias de lugar e espaço. Em outras palavras, como resultado do império da velocidade e do deslocamento - vetores diretamente associados ao poder tecnológico e à força bélica -, o meio atravessado passa a ser menos relevante do que a produção do movimento em si, fazendo com que a centralidade da noção de lugar ceda terreno para a afirmação do seu contrário, o não-lugar, caracterizado pela recusa da imobilidade, pelo deslocamento contínuo e pelo fluxo incessante. Conforme o autor, "o estreitamento das distâncias transformou-se numa realidade estratégica com consequências econômicas e políticas incalculáveis pois equivale à negação do espaço" (Virilio, 1996, p. 123). O espaço, agora atrelado à dormência, à falta de motricidade e à inação, deve também encolher com a diminuição das distâncias; já o seu inverso, a rapidez ilimitada, se revela o teste decisivo para as grandes potências: quanto mais desenvolvidas tecnicamente, quanto mais capazes de sofisticar seus dispositivos "dromológicos" de aceleração da vida e de celebração do progresso, tanto mais revelam sua verdadeira força econômica e militar. Nas palavras finais do autor, "a violência da velocidade tornou-se, simultaneamente, o lugar e a lei, o destino e a destinação do mundo"(Virilio, 1996, p. 137). 
O frágil corpo humano não passa impunemente pela negação sistemática do tempo inútil ou improdutivo, da desaceleração e do descanso. Cerca de uma década depois de Velocidade e política, agora em 1988, Paul Virilio publicou o livro intitulado Estética da desaparição, em que analisa o impacto da recusa do repouso e dos períodos de desconexão e ausência sobre a constituição psíquica dos sujeitos. Resumidamente, o autor parte do exemplo da pausa perceptiva provocada pela "picnolepsia" - um estado de interrupção da atenção que se assemelha a um pequeno ataque epilético, comum em crianças, causando a sensação de "ausência de mundo" e de catatonia - , a fim de demonstrar como a "sociedade dromológica" não consegue se reconciliar com a suspensão da vigília nem com a temporalidade disruptiva: o pequeno picnoléptico é forçado "a atestar acontecimentos que ele não viu, ainda que de fato tenham-se desenrolado em sua presença. Quando ele não consegue, é tratado como retardado e acusado de dissimulação e mentira" (Virilio, 2015, p. 19). A exigência de uma narrativa linear, capaz de restituir a ausência ao seu devido lugar no regime discursivo e comunicativo - que é, também, o regime da razão e da velocidade - , representa, no fundo, a mais profunda incapacidade de atribuir qualquer valor social àquilo que não tem utilidade ou aplicabilidade imediata e que, assim, passa a ser visto como mero obstáculo para as reivindicações capitalistas de circulação e funcionamento pleno. $\mathrm{O}$ caso do uso de automóveis, para Virilio (2015), é emblemático do desejo de movimento introjetado na sensibilidade e na subjetividade do sujeito cuja percepção atende às dinâmicas "dromológicas" do tempo presente:

Não ir a parte alguma, ou rodar em círculos num bairro deserto, ou numa autoestrada engarrafada, parecem naturais para o espectador-viajante. Ao contrário, parar e estacionar são operações desagradáveis. O motorista chega até a detestar ir a algum lugar ou procurar alguém; visitar uma pessoa ou ir a algum espetáculo parecem-lhe um esforço sobre-humano. Podendo atingir os locais mais distantes, ele só fica à vontade na célula estreita de seu veículo, cindido em seu assento. (Virilio, 2015, p. 72)

Mais que um lugar, um trajeto, uma pessoa, basta o vetor em si, a identificação com o vetor - nesse caso, o automóvel. Ora, se a literatura, por sua vez, exige concentração e lentidão, leitura atenta e reflexiva - se ela constitui, tal como o sono, tão somente uma pequena ilha ou parcela de intransitividade num cenário muito mais amplo e complexo de utilitarismo e aplicabilidade - , sua potência de fazer cessar o movimento e inaugurar uma temporalidade mais lenta representa um impasse, por menor que seja, às exigências de aceleração e produtividade constitutivas daquele mesmo capitalismo que não cansa de converter a escola numa pequena empresa, estimulando-a a mimetizar a sua linguagem corporativa. A BNCC, como visto, é parte de uma tentativa de atualizar a literatura e de conferir a ela um aspecto prático, materializando usos que, entretanto, acabam por destituir-lhe de sua negatividade e rebeldia constitutiva (cf. Cechinel, 2018). A pluralidade e a circularidade midiática que organizam o documento, e que deixam transparecer a ideia de que quanto mais, melhor, correspondem a um projeto de fazer acelerar, mover, veicular. 
As "competências e habilidades", que posicionam a ação política e intelectual no âmbito dos mesmos imperativos incontornáveis do tempo presente - "atuar de forma fundamentada, ética e crítica na produção e no compartilhamento de comentários, textos noticiosos e de opinião, memes, gifs, remixes variados etc. em redes sociais ou outros ambientes digitais" (Brasil, 2018, p. 522) — reduzem o campo do possível à reafirmação conformada do espetáculo integrado em que vivemos. Alinhada a esse circuito infinito de devices - dispositivos cuja sacralidade não deixa de contrastar com sua ciclicidade -, a literatura já não faz nada na escola senão anunciar a presença-ausente de um conceito que deverá acelerar a sua circulação e condição heteronômica até simplesmente evaporar e desaparecer como ideia.

\section{REFERÊNCIAS}

BERARDINELLI, A. Leer es um riesgo. Tradução de Salvador Cobo. Madri: Círculo de Tiza, 2016.

BOLTANSKI, L.; CHIAPELLO, È. O novo espírito do capitalismo. Tradução de Ivone C. Benedetti. São Paulo: Martins Fontes, 2009.

BRASIL. Orientações curriculares para o ensino médio. Brasília: Ministério da Educação/Secretaria de Educação Básica, 2006.v. 1.

BRASIL. Base Nacional Comum Curricular (Ensino Médio). Brasília: Ministério da Educação, 2018.

CANDIDO, A. O direito à literatura. In: CANDIDO, A. Vários escritos. 5. ed. Rio de Janeiro: Ouro sobre Azul, 2011.

CECHINEL, A. O ensino de literatura e a negatividade do literário. Pro-Posições, v. 29, n. 2, p. 285-298, maio/ago. 2018. http://dx.doi.org/10.1590/1980-6248-2016-0149

CRARY,J. Suspensões da percepção: atenção, espetáculo e cultura moderna. Tradução de Tina Montenegro. São Paulo: Cosac Naify, 2013.

CRARY, J. 24/7: capitalismo tardio e os fins do sono. Tradução de Joaquim Toledo Jr. São Paulo: Cosac Naify, 2014.

DARDOT, P.; LAVAL, C. A Nova Razão do Mundo: Ensaio sobre a Sociedade Neoliberal. Tradução de Mariana Echalar. São Paulo: Boitempo, 2016.

DEBORD, G.A sociedade do espetáculo: 50 anos mais atual do que nunca. Tradução de Estela dos Santos Abreu. 2. ed. Rio de Janeiro: Contratempo, 2017.

DURÃO, F.A. Teoria (literária) americana: uma introdução crítica. Campinas: Autores Associados, 2011.

DURÃO, F. A. O que é crítica literária. São Paulo: Nankin / Parábola, 2016.

GROS, F. Desobedecer. Tradução de Célia Euvaldo. São Paulo: Ubu, 2018.

HAN, B.-C. Sociedade do cansaço. Tradução de Enio Paulo Giachini. Petrópolis: Vozes, 2015.

HUTCHEON, L. Uma teoria da adaptação. Tradução de André Cechinel. Florianópolis: EdUFSC, 2011. 
INSTITUTO PRÓ-LIVRO. Retratos da leitura no Brasil. 4. ed. São Paulo: Instituto Pró-Livro, 2016. Disponível em: http://prolivro.org.br/home/images/2016/Pesquisa_ Retratos_da_Leitura_no_Brasil_-_2015.pdf. Acesso em: 5 out. 2018.

KRACAUER, S. O ornamento da massa: ensaios. Tradução de Carlos Eduardo Jordão Machado e Marlene Holzhausen. São Paulo: Cosac Naify, 2009.

LARROSA, J. Pedagogia profana. Tradução de Alfredo Veiga-Neto. 5. ed. Belo Horizonte: Autêntica, 2015.

ORGANIZAÇÃO PARA A COOPERAÇÃO E DESENVOLVIMENTO ECONÔMICO (OCDE). Competências para o progresso social: o poder das competências socioemocionais. Tradução de Maria Carbajal. São Paulo: Fundação Santillana, 2015.

TÜRCKE, C. A sociedade excitada: filosofia da sensação. Tradução de Antonio A. S. Zuin et al. Campinas: Editora da Unicamp, 2010.

VIRILIO, P. Velocidade e política. Tradução de Celso Mauro Paciornik. São Paulo: Estação Liberdade, 1996.

VIRILIO, P. Estética da desaparição. Tradução de Vera Ribeiro. Rio de Janeiro: Contraponto, 2015.

\section{SOBRE O AUTOR}

André Cechinel é doutor em literatura pela Universidade Federal de Santa Catarina (UFSC). Professor da Universidade do Extremo Sul Catarinense (UNESC).

E-mail: andrecechinel@gmail.com

Recebido em 08 de outubro de 2018

Aprovado em 21 de março de 2019 